\title{
Flora invasora de cultivos de aveia-preta, milho e sorgo em região de cerrado do Estado de Mato Grosso do Sul, Brasil
}

\author{
Adriana Guglieri-Caporal ( $\left.{ }^{*}\right)$; Francisco José Machado Caporal (1); Deborah Christiane Leite Kufner \\ ('); Fábio de Matos Alves (')
}

(') Universidade Federal de Mato Grosso do Sul (UFMS), Centro de Ciências Biológicas e da Saúde (CCBS), Departamento de Biologia (DBI), Cidade Universitária, Caixa Postal 549, 79070-900 Campo Grande (MS).

(*) Autora correspondente: adrianaguglieri@ig.com.br.

Recebido: 13/nov./2009; Aceito: 18/mai./2010.

\begin{abstract}
Resumo
Cerca de 3 milhões de hectares de solos de cerrado no Estado do Mato Grosso do Sul são ocupados por lavouras anuais como aveia-preta, milho e sorgo, nas quais ocorrem plantas invasoras. O primeiro requisito para o manejo e controle de plantas invasoras é a correta identificação. O presente trabalho teve como objetivo realizar o estudo florístico das espécies invasoras de cultivos de aveia-preta, milho e sorgo, em áreas de cerrado do Estado de Mato Grosso do Sul, para conhecimento sobre a diversidade em cada cultivo e a similaridade florística entre elas. Nos três cultivos estudados foi constatado o total de 14 famílias, 47 gêneros e 66 espécies invasoras. No cultivo de aveia-preta observou-se o maior número de espécies (43), seguido pelos de milho (39) e sorgo (29). As principais famílias em número de espécies foram Fabaceae (16), Poaceae (13) e Asteraceae (10). A maior similaridade florística ocorreu entre os cultivos de milho e sorgo $(0,588)$.

Palavras-chave: cultivos anuais, plantas daninhas, florística.
\end{abstract}

\section{Weed flora in black oats, corn and sorghum in the cerrado region of the State of Mato Grosso do Sul, Brazil}

\section{Abstract}

Around three million hectares of cerrado soils in Mato Grosso do Sul State are occupied by annual crops such as black oats, corn and sorghum, where occur weeds. The first requirement for management and control of weeds is the correct identification. The present work is a floristic survey of the weeds of black oats, corn and sorghum crops, in cerrado areas of Mato Grosso do Sul, aiming to know their diversity in each crop and the floristic similarity among them. In the three studied crops a total of 14 families, 47 genera and 66 weed species were found. Black oats presented the highest number of weed species (43), followed by corn (39) and sorghum (29). The main families in number of species were Fabaceae (16), Poaceae (13) and Asteraceae (10). The highest floristic similarity occurred between corn and sorghum (0.588).

Key words: annual crops, weed, floristics.

\section{INTRODUÇÃO}

Os solos do Cerrado possuem boa estrutura, o que, aliado ao relevo predominantemente plano ou suave ondulado, favorece a agricultura mecanizada (Prvello, 2006).

De acordo com a Produção Agrícola Municipal 2008 (IBGE, 2009), no Mato Grosso do Sul, as lavouras anuais totalizaram 3.237.782 hectares, destacandose a soja com 1.732.031 hectares. No Mato Grosso do Sul, cultiva-se em menor escala, aveia-preta (Avena strigosa Schreb.), milho-safrinha (Zea mays L.) e sorgo (Sorghum bicolor (L.) Moench) em rotação com a soja.

De maneira geral, as plantas invasoras requerem para seu desenvolvimento os mesmos fatores (água, luz, nutrientes e espaço físico) que a cultura, estabelecendo um processo de competiçáo e de interferência que pode ser determinado pela composição da flora invasora (espécie, densidade e distribuição), cultura (espécie ou variedade, espaçamento e densidade de plantio), ambiente (solo, clima), trato cultural (manejo) e período de convivência (Pitelli, 1985; Karam et al., 2006). Plantas invasoras podem diminuir a qualidade e o rendimento de um cultivo, dificultar a colheita e, em casos extremos, inviabilizá-la. Podem também elevar a umidade dos grãos e os custos de secagem, favorecer a fermentação e aumentar a incidência de pragas no armazenamento (VARGAS e RoMAn, 2005). Lorenzi (1976) estimou que as perdas culturais ocasionadas por plantas 
invasoras estão em torno de $30 \%$ a $40 \%$ e $20 \%$ a $30 \%$ referentes às produçóes agrícolas mundial e nacional, respectivamente.

Segundo Potт et al. (2006), o êxito no controle da comunidade invasora começa pelo levantamento (florística) das espécies infestantes e o conhecimento sobre a biologia daquelas predominantes.

Se manejadas adequadamente, as plantas invasoras podem aumentar a produtividade fornecendo alimento a predadores, parasitos e pragas (SouzA, 1991). KuUTHCOUSKI et al. (2003) salientaram o papel das invasoras como cobertura morta no sucesso do Sistema Plantio Direto (SPD), principalmente nos cerrados. Logo, o conhecimento sobre a diversidade das espécies invasoras pode contribuir no seu manejo em níveis que beneficiem sua participaçáo como fonte de alimento e incremento da cobertura morta.

Estudos recentes envolvendo a identificação da flora invasora de cultivos anuais foram realizados por Albertoni e Almeida Neto (1981), Macedo et al. (2003), Erasmo et al. (2004), Fontes et al. (2004), Fontes e Shiratsuchi (2005), Silva et al. (2005), Karam et al. (2006) e Duarte et al. (2007).

O presente trabalho teve como objetivo realizar o estudo florístico da comunidade invasora de cultivos de aveia-preta, milho e sorgo, em áreas de cerrado do Estado do Mato Grosso do Sul, para o conhecimento da diversidade em cada área e o cálculo da similaridade florística entre elas.

\section{MATERIAL E MÉTODOS}

Foram selecionados três cultivos temporários (aveia-preta, milho-safrinha e sorgo) em áreas de plantio de soja, em regiôes de cerrado de Campo Grande e Sidrolândia, municípios vizinhos, localizados na bacia hidrográfica do Rio Paraná, centro do Estado de Mato Grosso do Sul. As características gerais das áreas estudadas estão detalhadas na tabela 1 .

O clima na região conforme Köppen é do subtipo "Aw" tropical úmido, temperatura média de $24^{\circ} \mathrm{C}$, pre- cipitação pluvial média anual de $1500 \mathrm{~mm}$, com estação chuvosa no verão (outubro a abril) e seca no inverno; o relevo é suave ondulado com predomínio de Latossolo Vermelho-Escuro (Mato Grosso do Sul, 1990).

Foram realizadas análises química e física dos solos, a partir de três amostras compostas oriundas dos cultivos estudados (Tabela 2). As análises foram realizadas por Solos Laboratório de Análise, Consultoria e Informática Ltda. que segue a metodologia utilizada pela Embrapa Solos (SiLva et al., 1998).

As análises físicas e químicas dos solos das áreas de estudo demonstraram que são argilosos conforme o triângulo de classificação textural de solos (Lemos e Santos, 1996) e com pH moderadamente ácido de acordo com a EMBRAPA (2006). Revelaram também elevada saturação por bases, baixos teores de Al, e que o solo sob cultivo de aveia-preta é mais fértil que os sob milho e sorgo (Comissão de Fertilidade do Solo, 2004).

Foram realizadas visitas às áreas amostrais em julho de 2007 (período seco), visando ao levantamento da flora invasora, com coleta de material botânico, observação de espécies e populações no campo. Os espécimes coletados foram identificados com o uso de bibliografia especializada, comparaçấo com material de herbário e auxílio de especialistas. A nomenclatura de família e gênero está de acordo com APGII (2003). A abreviatura do nome dos autores das espécies seguiu Brummitt e Powell (1982). O material coletado, com flores e/ou frutos, foi herborizado conforme técnicas usuais e incorporado ao herbário CGMS da Universidade Federal de Mato Grosso do Sul.

Foram considerados os nomes populares conhecidos no Mato Grosso do Sul, obtidos através da literatura e consulta a moradores. Informações sobre a região de origem das espécies (nativa do Brasil ou exótica) foram obtidas na literatura.

As espécies foram classificadas quanto ao hábito (erva e subarbusto) de acordo Guedes-BRuni et al. (2002) e à forma biológica (hemicriptófita, terófita e geófita), conforme os grandes grupos do Sistema de Raunkier (1934), adaptado por Mǘller-Dombois e EllendBerg (1974). No presente estudo, foram consideradas as espécies com

Tabela 1. Características gerais das áreas estudadas de cultivo de aveia-preta, milho e sorgo em região de cerrado do Estado de Mato Grosso do Sul, em 2007

\begin{tabular}{|c|c|c|c|}
\hline Cultura & AVEIA- PRETA & MILHO & SORGO \\
\hline Localização & $\begin{array}{l}\text { Fazenda: Nova Esperança } \\
\text { Município: Sidrolândia } \\
\text { Coordenadas: } \\
20^{\circ} 45^{\prime} 34,5^{\prime} \text { 'S } 054^{\circ} 50^{\prime} 28,7^{\prime \prime} W\end{array}$ & $\begin{array}{l}\text { Fazenda: Luz da Lua } \\
\text { Município: Campo Grande } \\
\text { Coordenadas: } \\
20^{\circ} 35^{\prime} 33,1^{\prime \prime} \text { 'S } 054^{\circ} 44^{\prime} 47,2^{\prime \prime} \text { W }\end{array}$ & $\begin{array}{l}\text { Fazenda: Luz da Lua, } \\
\text { Município: Campo Grande } \\
\text { Coordenadas: } \\
20^{\circ} 36^{\prime} 12,9^{\prime \prime} \mathrm{S} 054^{\circ} 44^{\prime} 10,9^{\prime \prime} \mathrm{W}\end{array}$ \\
\hline Área total & 1 ha & 1 ha & 1 ha \\
\hline Idade & três meses & três meses & três meses \\
\hline Plantio & Direto & Direto & Direto \\
\hline Finalidade & Consumo animal (forragem verde) & Consumo animal (silagem) & Consumo animal (silagem) \\
\hline Cultura anterior/principal & Soja & Soja & Soja \\
\hline
\end{tabular}


Tabela 2. Análise granulométrica e química do solo das áreas estudadas de cultivo de aveia-preta, milho e sorgo em região de cerrado do Estado de Mato Grosso do Sul, Brasil (AVE = aveia; MIL = milho; SOR = sorgo; $\mathrm{pH}-1: 2.5 ; \mathrm{MO}-\mathrm{K}_{2} \mathrm{Cr}_{2} \mathrm{O}_{7} ; \mathrm{H}-$ acetato de cálcio (pH 7); P e K - extrator de Mehlich I; Ca e Mg - EDTA; S - Soma das Bases; T - Capacidade de Troca de Cátions; V - Saturação por Bases; $\mathrm{m}$ - Saturação por alumínio)

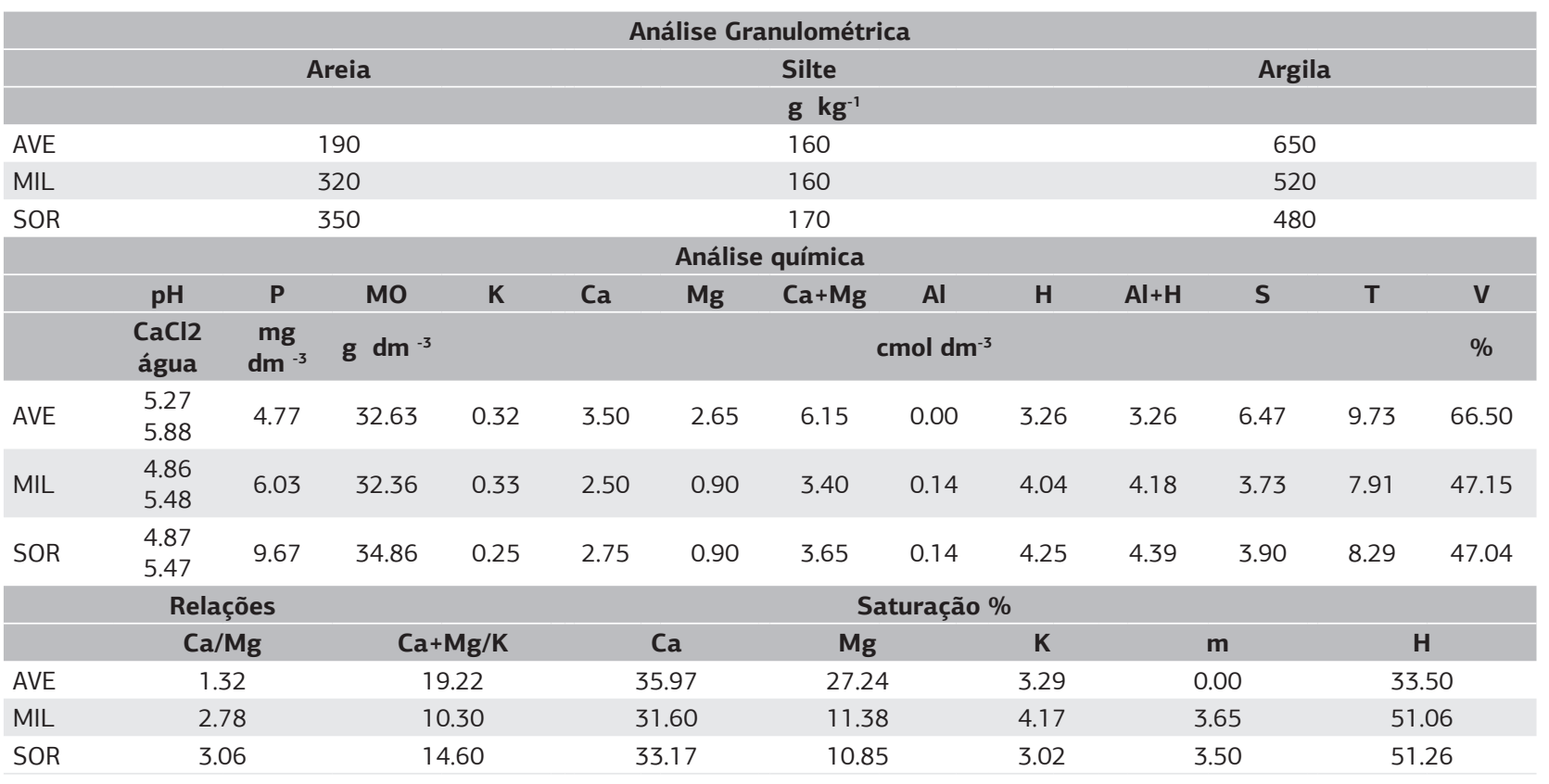

variação no hábito ou na forma biológica como grupos independentes. Estas informaçôes foram obtidas através da literatura e observações em campo.

Os valores de similaridade florística foram obtidos pelo Índice de Similaridade de Sorensen (ISS).

\section{RESULTADOS E DISCUSSÃO}

Nas três áreas estudadas, foi constatado o total de 14 famílias, 48 gêneros e 66 espécies de Fanerógamas invasoras (Tabela 3). O cultivo de aveia com maior número de espécies invasoras (43) foi seguido pelos de milho (39) e sorgo (29).

Do total de espécies amostradas, cerca de $79 \%$ são herbáceas, $12 \%$ são subarbustivas e $9 \%$ variam de herbáceas a subarbustivas. Em geral, as espécies herbáceas dominam o banco de sementes do solo, o que aliado ao seu caráter colonizador em ambientes alterados (Araujo et al., 2004) justificam seu predomínio nas áreas estudadas.

Em relação à origem, as exóticas representam cerca de $25 \%$ das espécies invasoras avaliadas.

Quanto à forma de vida, aproximadamente 55\% das espécies são terófitas, $38 \%$ são hemicriptófitas, $6 \%$ variam de terófitas a hemicriptófitas e $1 \%$ é geófita. As terófitas (anuais) garantem sua perpetuação por meio de sementes produzidas rapidamente e em grande quantidade, e que permanecem dormentes no período adverso. Já as hemicriptófitas e geófitas (perenes) não dependem exclusivamente de sementes para propagação e dispersão, utilizando estruturas vegetativas como rizomas, estolóes, tubérculos e bulbos para esse fim, o que as torna mais persistentes e de difícil controle (Dias Filho, 2007).

As principais famílias em número de espécies foram Fabaceae (16 espécies), Poaceae (13) e Asteraceae (10), que juntas correspondem a cerca de $59 \%$ do número total de espécies invasoras, e 51\%, 69\% e 69\% do número de espécies invasoras dos cultivos de aveia, milho e sorgo respectivamente. Estes resultados concordam com os observados por Albertoni e Almeida Neto (1981), Macedo et al. (2003), Fontes et al. (2004) e Fontes e ShiratsuCHI (2005), que também destacaram as referidas famílias dentre aquelas de maior número de espécies invasoras de cultivos de milho e outros anuais.

Considerando-se os três cultivos estudados, constatou-se que os gêneros com maior riqueza foram Sida, representado por cinco espécies, seguido de Chamaecrista com quatro, Amaranthus, Chamaesyce, Crotalaria, Digitaria e Zornia com três espécies cada uma. Resultado semelhante foi obtido por MACEDo et al. (2003), que destacaram Sida e Amaranthus com maior número de espécies em cultivos de milho.

Bidens pilosa (picão-preto), Ipomoea grandifolia (corda-de-viola) e Tridax procumbens (erva-de-touro), invasoras muito comuns em cultivos anuais e perenes da Regiáo Centro-Oeste (Kismman e Groth 1999; Lorenzi, 2000), foram constatadas nos três cultivos estudados (Tabela 3).

Bidens pilosa foi anteriormente citada como invasora de milho por Albertoni e Almeida Neto (1981), Garcia (1988), Macedo et al. (2003), Fontes et al. (2004), Fontes e Shiratsuchi (2005) e Duarte et al. (2007). Também foi mencionada como invasora de 
Tabela 3. Espécies invasoras observadas em cultivos de aveia-preta, milho e sorgo em região de cerrado do Estado de Mato Grosso do Sul, Brasil $(\mathrm{AV}$ = aveia, $\mathrm{MI}$ = milho, $\mathrm{SO}$ = sorgo; geo = geófita; hem = hemicriptófita; ter = terófita; her = herbácea; sub = subarbustiva; nat = nativa do Brasil; mat. est. = material estéril; CGMS = número de registro no herbário CGMS da Universidade Federal de Mato Grosso do Sul)

\begin{tabular}{|c|c|c|c|c|c|c|c|c|}
\hline Família/Espécie & Nome popular & AV & MI & so & $\begin{array}{l}\text { Forma de } \\
\text { vida }\end{array}$ & Hábito & Origem & CGMS \\
\hline \multicolumn{9}{|l|}{ AMARANTHACEAE } \\
\hline Amaranthus deflexus $L$. & caruru & - & $x$ & - & ter & her & Europa & 20086 \\
\hline Amaranthus hybridus L. & caruru & $x$ & - & - & ter & her & nat & 20042 \\
\hline Amaranthus cf. viridis L. & caruru & - & $x$ & - & ter & her & Caribe & 20115 \\
\hline \multicolumn{9}{|l|}{ APOCYNACEAE } \\
\hline Rhodocalyx rotundifolius Müll. Arg. & - & $x$ & - & - & hem & sub & nat & 21851 \\
\hline \multicolumn{9}{|l|}{ ASTERACEAE } \\
\hline Acanthospermum australe (Loefl.) Kuntze & carrapicho-de-carneiro & $x$ & - & $x$ & ter & her & nat & 20046 \\
\hline Bidens pilosa $\mathrm{L}$. & picão-preto & $x$ & $x$ & $x$ & ter & her & nat & 20043 \\
\hline Elephantopus mollis Kunth & fumo-bravo & $x$ & $x$ & - & hem & her & nat & 22007 \\
\hline Centratherum punctatum Cass. & perpétua & - & - & $x$ & hem & her & nat & 20349 \\
\hline Emilia sonchifolia (L.) DC. & emilia & $x$ & $x$ & - & ter & her & Ásia & 20069 \\
\hline Erechtites hieraciifolius (L.) Raf. ex DC. & voadeira & - & $\mathrm{x}$ & - & ter & her & nat & 20091 \\
\hline Galinsoga parviflora Cav. & picão-branco & - & $x$ & - & ter & her & nat & 20114 \\
\hline Gnaphalium pensylvanicum Willd. & - & - & $x$ & - & ter & her & nat & 20092 \\
\hline Porophyllum ruderale (Jacq.) Cass. & arnica & - & $x$ & $x$ & ter & her & nat & 20450 \\
\hline Tridax procumbens $\mathrm{L}$. & erva-de-touro & $x$ & $x$ & $x$ & ter & her & $\begin{array}{l}\text { América } \\
\text { Central }\end{array}$ & 20063 \\
\hline \multicolumn{9}{|l|}{ BRASSICACEAE } \\
\hline Raphanus raphanistrum L. & nabo & $x$ & - & $x$ & ter & her & Europa & 20067 \\
\hline \multicolumn{9}{|l|}{ CONVOLVULACEAE } \\
\hline Ipomoea cynanchifolia Meisn. & corda-de-viola & - & - & $x$ & ter & her & nat & 20095 \\
\hline Ipomoea grandifolia (Dammer) O’Donell & corda-de-viola & $x$ & $x$ & $x$ & ter & her & nat & 20041 \\
\hline \multicolumn{9}{|l|}{ EUPHORBIACEAE } \\
\hline Chamaesyce hirta (L.) Millsp. & quebra-pedra & $x$ & $x$ & $x$ & ter & her & nat & 20075 \\
\hline Chamaesyce hyssopifolia (L.) Small & leiteirinha & $x$ & $x$ & - & ter & her & nat & 20050 \\
\hline Chamaesyce thymifolia (L.) Millsp. & & $x$ & - & - & ter & her & nat & 20557 \\
\hline Euphorbia heterophylla L. & leiteira & $x$ & - & - & ter & her & nat & 20048 \\
\hline \multicolumn{9}{|l|}{ FABACEAE } \\
\hline \multirow[t]{2}{*}{ Arachis sp. } & amendoim-bravo & $x$ & $x$ & - & geo & her & - & mat. est. \\
\hline & - & - & $x$ & $x$ & hem & sub & nat & 20456 \\
\hline $\begin{array}{l}\text { Chamaecrista repens (Vogel) H.S. Irwin } \\
\text { \& Barneby }\end{array}$ & - & $x$ & - & - & hem & sub & nat & 20061 \\
\hline Chamaecrista rotundifolia (Pers.) Greene & - & $x$ & $x$ & $x$ & hem & her/sub & nat & 20056 \\
\hline Chamaecrista serpens (L.) Greene & - & - & $x$ & - & hem & her & nat & 20089 \\
\hline Crotalaria incana $\mathrm{L}$. & - & $x$ & - & - & ter & sub & nat & 21661 \\
\hline Crotalaria lanceolata E. Mey & - & - & $x$ & - & hem & her & África & 21693 \\
\hline Crotalaria stipularia Desv. & - & $x$ & $x$ & $x$ & hem & her/sub & nat & 21663 \\
\hline Desmodium incanum DC. & carrapicho & $x$ & - & - & hem & her/sub & nat & 20609 \\
\hline Glycine max (L.) Merr. & soja & $x$ & $x$ & $x$ & ter & her & China & 21664 \\
\hline Mimosa sp. & dorme-dorme & $x$ & - & - & hem & her & nat & mat. est. \\
\hline $\begin{array}{l}\text { Senna obtusifolia (L.) H.S. Irwin \& } \\
\text { Barneby }\end{array}$ & fedegoso & $x$ & $x$ & - & ter & sub & nat & 20073 \\
\hline Stylosanthes bracteata Vogel & estilosantes & $x$ & - & $x$ & hem & her/sub & nat & 20610 \\
\hline Zornia cf. curvata Mohlenbr. & - & - & - & $x$ & hem & her & nat & 20347 \\
\hline Zornia latifolia Sm. & orelha-de-caxinguelê & - & - & $x$ & hem & her & nat & 20350 \\
\hline Zornia sp. & - & - & $x$ & - & hem & her & - & 20346 \\
\hline \multicolumn{9}{|l|}{ LAMIACEAE } \\
\hline Leonotis nepetifolia (L.) R. Br. & $\begin{array}{l}\text { cordão-de-são- } \\
\text { francisco }\end{array}$ & $x$ & - & - & ter & her/sub & África & 20055 \\
\hline Leucas martinicensis (Jacq.) R. Br. & hortelã & $x$ & $x$ & - & ter & her & $\begin{array}{l}\text { América } \\
\text { Central }\end{array}$ & 20045 \\
\hline
\end{tabular}


Tabela 3. Conclusão

\begin{tabular}{|c|c|c|c|c|c|c|c|c|}
\hline Família/Espécie & Nome popular & AV & MI & so & $\begin{array}{l}\text { Forma de } \\
\text { vida }\end{array}$ & Hábito & Origem & CGMS \\
\hline \multicolumn{9}{|l|}{ MALVACEAE } \\
\hline Corchorus hirtus L. & - & $\mathrm{x}$ & $x$ & - & ter & her & nat & 20090 \\
\hline Sida cerradoensis Krap. & malva & - & $x$ & $x$ & hem & her & nat & 20098 \\
\hline Sida cordifolia L. & guanxuma & $x$ & - & - & hem & sub & nat & 20059 \\
\hline Sida linifolia Cav. & malvinha & $x$ & $x$ & - & ter & her & nat & 20344 \\
\hline Sida rhombifolia L. & guanxuma & $x$ & $x$ & $x$ & ter/hem & her & nat & 20047 \\
\hline Sida urens L. & guanxuma & $x$ & $x$ & - & ter & her & nat & 20080 \\
\hline Triumfetta bartramia L. & - & $x$ & - & - & hem & sub & nat & 20083 \\
\hline Waltheria indica L. & malva-branca & $x$ & - & $x$ & hem & her & nat & 20051 \\
\hline \multicolumn{9}{|l|}{ MENISPERMACEAE } \\
\hline Cissampelos ovalifolia DC. & - & $x$ & - & - & hem & sub & nat & 20448 \\
\hline \multicolumn{9}{|l|}{ PHYLLANTHACEAE } \\
\hline Phyllanthus orbiculatus Rich. & quebra-pedra & - & - & $x$ & ter & her & nat & 22008 \\
\hline \multicolumn{9}{|l|}{ POACEAE } \\
\hline Avena sativa $\mathrm{L}$. & aveia-branca & - & $x$ & - & ter & her & $\begin{array}{l}\text { Velho } \\
\text { Mundo }\end{array}$ & 20729 \\
\hline Cenchrus echinatus L. & carrapicho & $x$ & $x$ & $x$ & ter & her & nat & 20044 \\
\hline Chloris elata Desv. & - & $x$ & $x$ & $x$ & hem & her & nat & 20049 \\
\hline Digitaria bicornis (Lam.) Roem. \& Schult. & capim-de-capoeira & - & $x$ & $x$ & ter & her & nat & 20731 \\
\hline Digitaria horizontalis Willd. & milhã & - & $x$ & $x$ & ter & her & nat & 20727 \\
\hline Digitaria insularis (L.) Fedde & amargoso & $x$ & $x$ & - & hem & her & nat & 20723 \\
\hline Echinochloa colona (L.) Link & - & - & $x$ & $x$ & ter & her & $\begin{array}{l}\text { Europa/ } \\
\text { Ásia }\end{array}$ & 20725 \\
\hline Eleusine indica (L.) Gaertn. & pé-de-galinha & - & $\mathrm{x}$ & $x$ & ter & her & $\begin{array}{l}\text { Velho } \\
\text { Mundo }\end{array}$ & 20726 \\
\hline Hyparrhenia rufa (Nees) Stapf. & capim-jaraguá & $x$ & - & - & hem & her & África & 21666 \\
\hline Melinis repens (Willd.) Zizka & capim-favorito & $x$ & $x$ & $x$ & ter/ hem & her & África & 21696 \\
\hline Setaria parviflora (Poir.) Kerguélen & capim-suçarana & - & $x$ & $x$ & ter/ hem & her & nat & 20728 \\
\hline $\begin{array}{l}\text { Urochloa brizantha (Hochst. ex A. Rich.) } \\
\text { R.D. Webster }\end{array}$ & brizantão & $x$ & - & - & hem & her & África & 21133 \\
\hline Zea mays L. & milho & $x$ & - & - & ter & her & México & 20724 \\
\hline \multicolumn{9}{|l|}{ RUBIACEAE } \\
\hline Borreria sp. & - & $x$ & - & - & hem & her & - & 20215 \\
\hline Mitracarpus hirtus (L.) DC. & - & $x$ & - & - & ter & her & nat & 20066 \\
\hline Richardia brasiliensis Gomes & - & - & $\mathrm{x}$ & $x$ & ter & her & nat & 20088 \\
\hline \multicolumn{9}{|l|}{ SOLANACEAE } \\
\hline Solanum viarum Dunal & joá, juá-bravo & $x$ & - & - & ter/ hem & her/sub & nat & 20611 \\
\hline
\end{tabular}

arroz, café, soja (Albertoni e Almeida Neto, 1981), feijão (Silva et al., 2005), algodão (Albertoni e Almeida Neto, 1981; KLein, 1989), cana-de-açúcar (Kuva et al., 2007) e mandioca (Peressin et al., 1998). Segundo SANTos et al. (2003), B. pilosa se destaca como invasora pela sua agressividade, competitividade e intensidade de ocorrência. Um indivíduo pode produzir até 3000 aquênios, geralmente com boa viabilidade, tanto em plena insolação quanto em iluminação difusa (KIssmann e Groth, 1999), o que favorece o estabelecimento e a propagaçáo nos mais diferentes cultivos. Além disso, suas sementes permanecem viáveis no banco de sementes do solo por três ou quatro anos (Voll et al., 2005).

Ipomoea grandifolia foi mencionada como invasora de milho por Macedo et al. (2003) e Fontes e ShiratsUCHI (2005). Também foi constatada em arroz (ERAS-
Mo et al., 2004), feijão (Silva et al., 2005) e cana-deaçúcar (Kuva et al. 2007).

Bidens pilosa e Ipomoea grandifolia são também invasoras de grande ocorrência em silvicultura (eucalipto e acácia) e em pastagens cultivadas.

Tridax procumbens foi observada como invasora em cultivos de milho (Macedo et al., 2003; Fontes et al. 2004; Fontes e Shiratsuchi 2005) e cana-de-açúcar (Kuva et al., 2007). Acanthospermum australe (carrapichode-carneiro) não foi observada no cultivo de milho estudado, entretanto, foi citada como invasora desta cultura por Albertoni e Almeida Neto (1981); Macedo et al. (2003). É considerada muito comum em lavouras em áreas de campo e cerrado, onde é uma das primeiras espécies a ocorrer, e, sob condiçóes favoráveis, como boa umidade e iluminação abundante, desenvolve-se e alastra-se 
rapidamente (Lorenzi, 2000; Kissmann e Groth, 1999), tendo sido constatada em cultivos de algodão (ALbertoni e Almeida Neto, 1981; Klein, 1989), arroz e soja (Albertoni e Almeida Neto, 1981).

De acordo com Fernandes (2006), no SPD, a palhada pode reduzir a propagação da vegetação invasora. Pereira e Velini (2003) mencionaram que a escolha de um programa de rotação de culturas pode definir o comportamento evolutivo da comunidade invasora, e concluíram que, sob o SPD, a rotação de culturas milho safrinha/soja é uma das que tem maior eficiência no controle das invasoras, o que pode explicar a baixa diversidade florística no cultivo de milho do presente estudo. Apesar da alta diversidade da flora invasora observada no cultivo de aveia-preta estudado, RIZZARDI e SILVA (2006) salientaram a sua importância na rotação de culturas sob SPD, em razão de sua contribuição para melhoria das propriedades físicas, químicas e biológicas do solo e pela lenta decomposição da palhada.

As gramíneas representaram aproximadamente 16\% do total de espécies constatadas no cultivo de aveia-preta, concordando com o mencionado por Kichel e Miranda (2000). Segundo esses autores, as principais invasoras de cultivo de aveia são as plantas ditas de folha larga, em contraposição às gramíneas. As gramíneas corresponderam a cerca de $26 \%$ e $28 \%$, respectivamente, nos cultivos de milho e sorgo, evidenciando também a predominância de espécies de folhas largas.

De acordo com Pitelli (1985), as diferentes espécies de plantas cultivadas variam bastante em suas capacidades de suportar a competição imposta pelas plantas invasoras. Segundo esse mesmo autor, culturas como o milho são mais competitivas do que aquelas de baixo porte e reduzido poder de interceptaçáo da luz solar, o que foi observado no presente estudo. A reduçáo da quantidade e a alteração da qualidade da luz solar, imposta pelas plantas de milho e sorgo, que possuem grande porte e alto índice de área foliar, durante os períodos de germinação de sementes e desenvolvimento de plântulas podem ter contribuído para a menor diversidade florística nesses cultivos, quando comparada à da aveia-preta. A considerável exposiçáo à luz solar, facilitada pelo baixo porte de aveiapreta, pode também ter contribuído com a germinaçáo de sementes e com o desenvolvimento de plântulas de muitas espécies, propiciando maior infestação por espécies que preferem ambientes ensolarados, como Acanthospermum australe (carrapicho-de-carneiro), Emilia sonchifolia (emilia), Chamaesyce hyssopifolia (leiteirinha) e Tridax procumbens (erva-de-touro). Estas espécies não ocorreram ou infestaram levemente os cultivos de milho e sorgo.

Pitelli (1985) salientou que a fertilidade do solo influencia ao mesmo tempo o crescimento da cultura e das plantas invasoras, o que pode ter contribuído com a maior diversidade da comunidade invasora do cultivo de aveia-preta, localizada em solo mais fértil como mencionado anteriormente.
Pitelli (1985) também mencionou que a existência do fenômeno alelopático é de grande importância na determinação do balanço da interferência cultura-comunidade invasora. Em um determinado cultivo, plantas invasoras com potencial alelopático podem interferir no desenvolvimento da cultura, o que pode causar sérios danos à produçấo. Por outro lado, plantas cultivadas também podem produzir substâncias alelopáticas que interferem no crescimento de espécies invasoras. Compostos de potencial alelopático são exsudados das raízes de sorgo e também liberados através da decomposição de resíduos das raízes e da parte aérea (VIDAL e TreZzI, 2004; TreZZI e VIDAL, 2004), capazes de agir sobre o crescimento de algumas espécies de Amaranthus, Digitaria e Echinochloa, mas não de Ipomoea (Trezzi et al., 2005). Amaranthus deflexus (caruru), A. cf. viridis, Echinochloa colona, Digitaria horizontalis (milhã) e D. insularis (amargoso), frequentes no cultivo de milho, não foram constatadas no de sorgo, o que pode estar relacionado a substâncias alelopáticas desta última cultura, concordando com Trezzi et al. (2005). Portanto, além do sombreamento imposto pelo sorgo, anteriormente mencionado, seu potencial alelopático pode ter também contribuído para a baixa diversidade de espécies invasoras observadas na área de cultivo estudada. Já Ipomoea grandifolia, assim como em aveia e milho, destacou-se como uma das espécies mais comuns do cultivo de sorgo, o que também está de acordo com o salientado pelo referido autor. Por outro lado, na área de sorgo foram observados em diferentes pontos indivíduos isolados de Digitaria bicornis (capim-de-capoeira), o que permite inferir sobre a possibilidade desta espécie ser resistente às substâncias alelopáticas do sorgo, vindo a se tornar, quando não combatida, uma potencial invasora.

Kissmann e Groth (2000) salientaram o forte potencial alelopático da aveia-preta, entretanto, os resultados observados quanto à diversidade e riqueza de plantas invasoras no presente estudo náo parecem concordar com esse fato.

Do número total de espécies invasoras constatadas nos cultivos de aveia-preta, milho e sorgo estudados, aproximadamente $17 \%$ são comuns aos três cultivos e, respectivamente, em torno de $27 \%, 14 \%$ e $8 \%$ das espécies são exclusivas de cada cultivo, Pelo índice de Sorensen (ISS), foram obtidos os seguintes valores para similaridade florística: aveia x milho, ISS $=0,5122$; aveia $\mathrm{x}$ sorgo, ISS $=0,4167$; milho $\mathrm{x}$ sorgo, ISS $=0,5883$. Tal resultado permite inferir que maior semelhança entre fatores como grau de sombreamento gerado pela cultura, características do solo (granulometria e fertilidade) e proximidade geográfica contribuíram com maior similaridade florística entre os cultivos de milho e sorgo.

\section{CONCLUSÃO}

A composição florística da comunidade invasora varia com a cultura, sendo a maior diversidade verificada no 
cultivo de aveia-preta e a maior similaridade observada entre os cultivos de milho e sorgo.

Os resultados dos levantamentos florísticos efetuados podem vir a auxiliar na adoção de procedimentos de controle das invasoras de culturas e servir de subsídios para estudos florísticos, fitossociológicos, agronômicos e bioquímicos futuros, envolvendo a comunidade invasora de cultivos em regiōes de cerrado.

\section{AGRADECIMENTOS}

Os autores agradecem a MSc. Vali Joana Pott e ao Dr. Arnildo Pott por identificaçôes botânicas. A este último, também agradecemos pela revisão do artigo e suas sugestóes. À Coordenação de Aperfeiçoamento de Pessoal de Nível Superior - CAPES, pelo apoio à realização deste trabalho.

\section{REFERÊNCIAS}

ALBERTONI, M.R.; AMEIDA NETO, J.X. Principais plantas daninhas que infestam as culturas de algodão, arroz, café, milho, soja e pastagens no Estado de Goiás. Anais da Escola de Agronomia e Veterinária, v.11, p.44-55, 1981.

APG (Angiosperm Phylogeny Group) II. An update of the Angiosperm Phylogeny Group classification for the orders and families of flowering plants: APG II. Botanical Journal of Linnean Society, v.141, p.399-436, 2003.

ARAUJO, M.M.; LONGHI, S.J.; BARROS, P.L.C. de; BRENA, D.A. Caracterizaçáo da chuva de sementes, banco de sementes do solo e banco de plântulas em Floresta Estacional Decidual ripária Cachoeira do Sul, RS, Brasil. Scientia Forestalis, v. 66, 128-141, 2004.

BRUMMITT, R.K.; POWELL, C.E. Authors of plant names. Kew: The Royal Botanic Gardens, 1992. 732p.

COMISSÃO DE FERTILIDADE DO SOLO - RS/SC. Recomendaçôes de adubação e de calagem para os estados do Rio Grande do Sul e de Santa Catarina. 10.ed. Passo Fundo: SBCS Núcleo Regional Sul, 2004. 224 p.

DIAS FILHO, M.B. Degradação de pastagens: processos, causas e estratégias de recuperação. Belém: Embrapa Amazônia Oriental, 2007. 190p.

DUARTE, A.P.; SILVA, A.C.; DEUBER, R. Plantas infestantes em lavouras de milho safrinha, sob diferentes manejos, no Médio Paranapanema. Planta Daninha, v.25, p. 285-291, 2007.

EMBRAPA SOLOS. Sistema Brasileiro de Classificação de solos. Rio de Janeiro: Embrapa Solos, 2008. Disponível em: <www.cnps. embrapa.br/sibcs>. Acesso em: 28 ago. 2008.

ERASMO,E.A.L.; PINHEIRO,L.L.A.; COSTA, N.V.Levantamento fitossociológico das comunidades de plantas infestantes em áreas de produção de arroz irrigado cultivado sob diferentes sistemas de manejo. Planta Daninha, v.22, p.195-201, 2004.
FERNANDES, B. Cobertura vegetal do solo. Manah Informativos, ano XXIV, n. 170, p. 1-6, 2006.

FONTES, J.R.A.; SHIRATSUCHI, L.S. Levantamento florístico de plantas daninhas em lavoura de milho cultivada no Cerrado de Goiás. Planaltina: Embrapa Cerrados 2005. 19p. (Boletim de Pesquisa e Desenvolvimento, 144)

FONTES, J.R.A.; SHIRATSUCHI, L.S.; SILVA, R.R. Levantamento florístico de plantas daninhas em cultura de milho irrigado em Luís Eduardo Magalhães - BA. Ciência das Plantas Daninhas, v.10, p.5-8, 2004.

GUEDES-BRUNI, R.R.; MORIM,M.P.; LIMA,H.C.; SILVESTRE, L.S. Inventário florístico. In: SYLVESTRE, L.S.; ROSA, M.M.T. (Orgs.). Manual metodológico para estudos botânicos na Mata Atlântica. Rio de Janeiro: Seropédica, p.24-49, 2002.

IBGE. Produção Agrícola Municipal 2008. Rio de Janeiro: IBGE, 2009. Disponível em: <www.ibge.gov.br>. Acesso em: 12 jan. 2010 .

KARAM, D.; MELHORANÇA, A.L.; OLIVEIRA, M.F. de. Plantas daninhas na cultura do milho. Ministério da Agricultura, Pecuária e Abastecimento 2006. 7p. (Circular Técnica, 79)

KICHEL, A.N.; MIRANDA, C.H.B. Uso da aveia como planta forrageira. Gado de corte divulga, v.45, p.1-5, 2000.

KISSMANN, K.G.; GROTH, D. Plantas infestantes e nocivas. 2.ed. Tomo II. São Paulo: BASF, 1999. 978p.

KISSMANN, K.G.; GROTH, D. Plantas infestantes e nocivas. 2.ed. Tomo III. São Paulo: BASF, 2000. 726p.

KLUTHCOUSKI, J.; COBUCCI, T.; AIDAR, H. COSTA, J.L. da S.; PORTELA, C. Cultivo do feijoeiro em palhada da braquiária. Santo Antônio de Goiás: Embrapa Arroz e Feijão, 2003. 28p. (Documentos, 157)

KUVA, M.A.; PITELLI, R.A.; SALGADO, T.P.; ALVES, P.L.C.A. Fitossociologia de comunidades de plantas daninhas em agroecossistema cana-crua. Planta Daninha, v. 25, p.501-511, 2007.

LEMOS, R.C.; SANTOS, R.D. Manual de descriçấo e coleta de solo no campo. 3. ed. Campinas: Sociedade Brasileira de Ciência do Solo, 1996. 83p.

LORENZI, H. Principais ervas daninhas do estado do Paraná. Londrina: IAPAR 1976. 208p. (Boletim Técnico, 2)

LORENZI, H. Plantas daninhas do Brasil: terrestres, aquáticas, parasitas e tóxicas. 3. ed. Nova Odessa: Instituto Plantarum, 2000. $608 \mathrm{p}$.

MACEDO, J.F.; BRANDÃO, M.; LARA, J.F.R. Plantas daninhas na pós-colheita de milho nas várzeas do Rio São Francisco, em Minas Gerais. Planta Daninha, v.21, p. 239-248. 2003.

MATO GROSSO DO SUL - Secretaria de Planejamento e Coordenação Geral. Atlas Multirreferencial. Campo Grande: IBGE, 1990. 27p. 
MÜELLER-DOMBOIS, D.; ELLENBERG, H. Aims and methods of vegetation ecology. New York: John Wiley \& Sons, 1974. $547 \mathrm{p}$.

PEREIRA, F.A.R.; VELINI, E.D. Sistemas de cultivo no cerrado e dinâmica de populaçôes de plantas daninhas. Planta Daninha, v.21, p.355-363, 2003.

PERESSIN, V.A.; MONTEIRO, D.A.; LORENZI, J.O.; DURIGAN, J.C.; PITELLI, R.A.; PERECIN, D. Acúmulo de matéria seca na presença e na ausência de plantas infestantes no cultivo de mandioca SRT 59-branca de Santa Catarina. Bragantia, v.57, p.135-148, 1998.

PITELLI, R.A. Interferência de plantas daninhas em culturas agrícolas. Informe Agropecuário, v.11, p.16-27, 1985.

PIVELLO, V.R. Invasões biológicas no Cerrado Brasileiro: efeitos da introdução de espécies exóticas sobre a Biodiversidade. Ecologia. Info 33, 2006. Disponível em: <www.ecologia.info> Acesso em: 20 fev. 2007.

POTT, A.; POTT, V.J.; SOUZA, T.W. de. Plantas daninhas de pastagem na Região dos Cerrados. Corumbá: Embrapa Gado de Corte, 2006. 336p.

RIZZARDI, M.A.; SILVA, L.F. Influência das coberturas vegetais antecessoras de aveia-preta e nabo forrageiro na época de controle de plantas daninhas em milho. Planta Daninha, v.24, p.669-675, 2006.

SANTOS, J.B.S.; PROCÓPIO, S.O.; SILVA, A.A.; COSTA, L.C. Captação e aproveitamento da radiação solar pelas culturas da soja e do feijão e por plantas daninhas. Bragantia, v.62, p.147-153, 2003.
SILVA, A.A.; SILVA, C.S.W.; SOUZA, C.M.; SOUZA, B.A.; FAGUNDES, J.L.; FALLEIRO, R.M.; SEDIYAMA, C.S. Aspectos fitossociológicos da comunidade de plantas daninhas na cultura do feijão sob diferentes sistemas de preparo do solo. Planta Daninha, v.23, p.17-24, 2005.

SILVA, F.C.; EIRA, P.A.; BARRETO, W.O.; PEREZ, D.V.; SILVA, C.A. Análises químicas para avaliaçáo da fertilidade do solo. Métodos usados na Embrapa Solos. Rio de Janeiro: Embrapa Solos ,1998. 40p. (Documentos, 3)

SOUZA, I.F. Controle biológico de plantas daninhas. Informe Agropecuário, v.15, p. 77-82, 1991.

TREZZI, M.M.; VIDAL, R.A. Potencial de utilizaçáo de cobertura vegetal de sorgo e milheto na supressão de plantas daninhas em condição de campo: II - Efeitos da cobertura morta. Planta Daninha, v.22, p.1-10, 2004

TREZZI, M.M.; VIDAL, R.A.; KRUSE, N.D. Fitotoxicidade de extratos hidrofóbicos e hidrofílicos de sorgo e milheto. Revista de Ciências Agroveterinárias, v.4, p.25-34, 2005.

VARGAS, L.; ROMAN, E.S. Seletividade e eficiência de herbicidas em cereais de inverno. Revista Brasileira de Herbicidas, n.3, p.1-10, 2005.

VIDAL, R.A.; TREZZI, M.M. Potencial da utilização de coberturas vegetais de sorgo e milheto na supressão de plantas daninhas em condição de campo: I - Plantas em desenvolvimento vegetativo. Planta Daninha, v.22, p.217-223, 2004.

VOLL, E.; GAZZIERO, D.L.P.; BRIGHENTI, A.M.; ADEGAS, F.S.; GAUDÊNCIO, C.A.; VOLL, C.E. A dinâmica das plantas daninhas e práticas de manejo. Londrina: Embrapa Soja 2005. 85p. (Documentos, 260) 